\title{
CityScope Platform for Real-Time Analysis and Decision-Support in Urban Design Competitions
}

\author{
Jesús López Baeza, HafenCity University, Germany \\ (iD) https://orcid.org/0000-0002-4092-1782 \\ Julia L. Sievert, HafenCity University, Germany \\ André Landwehr, HafenCity University, Germany \\ Jonas Luft, HafenCity University, Germany \\ Philipp Preuner, HafenCity Hamburg GmbH, Germany \\ Jürgen Bruns-Berentelg, HafenCity Hamburg GmbH, Germany \\ Ariel Noyman, Massachusetts Institute of Technology, USA \\ Joerg Rainer Noennig, HafenCity University, Germany \\ (iD https://orcid.org/0000-0002-1681-7635
}

\begin{abstract}
This paper presents a digital online tool and interaction process that supplies algorithmic analysis and predictive simulation for early-stage urban design proposals within the framework of public competitions. Specifically, the system supports the decision-making of two user groups: 1) planners in the process of developing urban designs proposals and 2) competition juries in evaluating those proposals. The system provides instant assessment of the design solutions' environmental and spatial impact regarding selected target criteria such as noise propagation or pedestrian accessibility. Enabling the easy testing of functional programs and the identification of feasible trade-offs between multiple design targets, the system supports rapid design iterations as well as the objective evaluation of proposals. Applied for the first time within an innovative tender format for a new residential and business district in Hamburg, Germany, the new toolset paves the way towards a more holistic and interactive form of sustainable urban design.
\end{abstract}

\section{KEYWORDS}

CityScope, Co-Creation, Decision-Making, Digital Tool, Environmental Impact Analyses, Urban Planning

\section{INTRODUCTION}

Urban design and development projects evolve through a complex and lengthy process. From project initiation via stages of public deliberation and tendering up to the physical execution of urban and architectural designs, a multitude of stakeholders, functional requirements, and target criteria need to be coordinated and harmonised (Alexander \& Witzling, 1990). Within this process, the results of 
early-stage urban design competitions play a crucial role, as their procedures and outcomes strongly determine the shape and quality of future urban environments (Alaily-Mattar \& Thierstein, 2018).

This paper presents ongoing research and innovation cooperation aiming for a novel methodology for urban design competitions, with the goal of providing real-time analysis and instant decision support.

The key idea is the application of the CityScope, a digital instrument that supplies algorithmic analysis and predictive simulation to planners and decision-makers in the various development stages of an urban design endeavour. The presented new tool and methodology focus on early-stage design proposals and can assess their performance in regards to environmental and spatial impact. Iterative, interactive, and participative in nature, the CityScope-based approach aims to "reinvent" the conventional formats of design competitions by going beyond their linear and deterministic procedures, as well as beyond their limited capacities in terms of urban analysis and simulation. Addressing planning offices participating in urban design competitions, the presented tool and methodology help to visualize quickly and in detail selected key performance indicators of design proposals while they are being generated, or already submitted.

In the context of urban design competitions, the proposed system addresses two specific use cases. The first one considers its usage by design studios in the earliest phase of design work, in which schematic proposals are drafted that outline elementary functional and spatial features of a future urban area. For this case, the system was designed to rapidly deliver information and realtime interaction which in turn enables urban designers to observe the environmental effects of the proposals, to estimate their overall qualitative performance, and to optimize their spatial layout and functional programs. For example, the toolset may provide instant answers to questions like: "How does the placement of a certain building in a certain location influence the propagation of traffic noise in the entire area?" The real-time calculation and visualization of the results may substantially enhance the ongoing design work and subsequent decision making processes.

The second use case of the system considers the concluding phases of design competitions when multiple designs have been submitted and expert juries assess them. At this stage, the CityScope system helps the jurors to evaluate the completeness of submissions, to check their compliance with key competition criteria, and to judge the different proposals on the basis of unified and objective performance indicators. The comparison of design proposals by way of algorithmic analysis benefits an unbiased and transparent assessment process, and also eases the challenge for juries facing the task of assessing proposals which were submitted in inconsistent or non-standardized formats (e.g. physical models, perspective drawings, text descriptions).

The presented research and innovation endeavour is a cooperation of three institutional partners. HafenCity Hamburg GmbH leads the institutional cooperation. It is a city-owned urban development agency mandated to develop large-scale projects in the city of Hamburg, such as the HafenCity, Europe's largest inner-city urban regeneration project, which has been under development for the past two decades (Christiaanse et al., 2019; Lehmann, 2019 Burdett \& Rode, 2018). Two academic research groups active in the field of Digital City Science complete the consortium. The City Science Group at the MIT Media Lab (Cambridge, Massachusetts) is the originator of the interactive modelling technology CityScope, and has explored its potentials for rapid design prototyping and analysis over the past decade, branching its application scope into multiple directions over the globe (Noyman, 2015; Alrashed et al., 2015; Hadhrawi \& Larson, 2016). Following that path, the Digital City Science at HafenCity University has developed and implemented the adaptation of the existing tool as well as the analytic modules described in this contribution, in cooperation with local authorities and agencies in creating a comprehensive toolbox of digital instruments that address specific urban development challenges in Hamburg. The common denominator of this partnership is the idea of a scientific, evidence-based approach to urban development that exploits all possibilities of state-of-the-art digital technology and data analysis. 


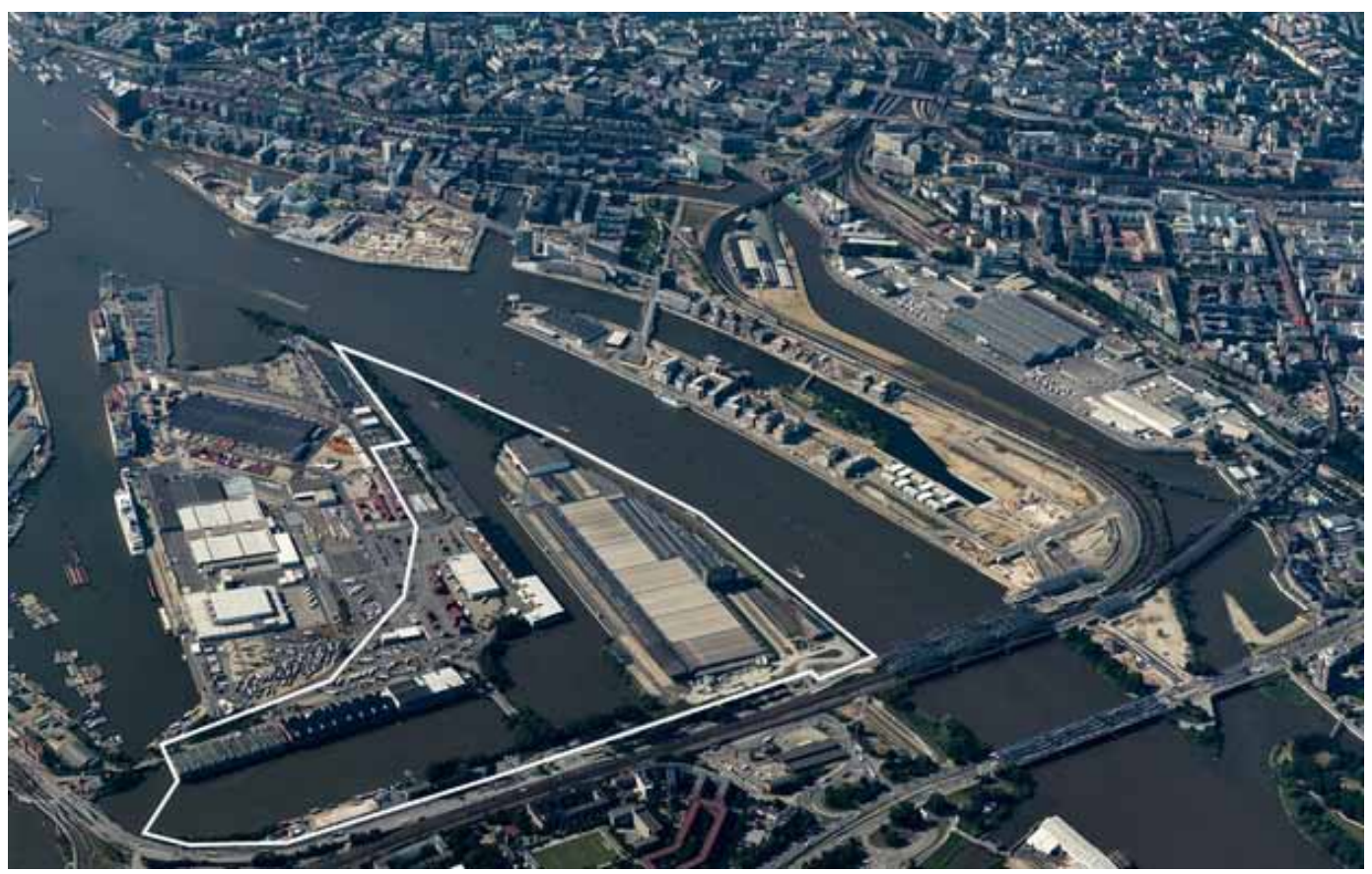

The CityScope system has been deployed in the context of public participatory actions or public consultation (Noyman et al., 2017) in line with other actions in the field of Tulloch's (2008) definition of Public Participatory Geographic Information Systems (PPGIS) exemplified by Panek, Paszto \& Marek (2017) and subsequent work on the topic of "emotional mapping". In contrast to these application cases, the analytic modules described in this contribution do not consider their implementation in a public participation use case, and are not designed for its use by the general public. Instead, they are closer to Burian et al.'s (2015) description of analytic extension modules added to a baseline software in order to simulate scenarios by testing urban characteristics. While Burian et al.'s Urban Planner is adapted to the specificity of their research and works at a small scale, the CityScope analytic modules described in this paper aims at a micro-scale approach and a replicable methodology.

\section{The Case: Grasbrook Hamburg}

The format of the "Competitive Dialogue" is a legal tender framework particularly for complex and innovative projects (Haugbølle et al., 2015). In the case of Grasbrook, the tender was announced EUwide (HafenCity Hamburg GmbH, 2019). Six urban design offices and six landscape design offices were invited. These design teams worked independently within their specific professional scopes as urban or landscape designers. After a first conceptual phase, six offices were selected and matched into three mixed teams in December 2019, who were to deliver a proposal comprehending landscape and urban design solutions. After this second phase, one winning team was selected by a high-level jury in April 2020. In the second phase, the selected teams were not permitted to cooperate, except for the matched offices. The HafenCity Hamburg $\mathrm{GmbH}$, that published and managed the tender, acted as an intermediary between ministries, citizens, experts and design teams in order to supply data and feedback for the iterative improvement of their design schemes.

The tender was accompanied by an intensive public deliberation process as well as by expert analyses, all of which fed into the jury decision. The preparation of the tender document already included documentation of several thematic citizen workshops on living, working, mobility, 
sustainability and architecture, carried out between December 2018 and March 2019. During the competition, design teams presented their work in progress in public events and discussed them with citizens. To incorporate professional expert knowledge as well, engineering consultants were requested to simulate noise, microclimate, wind, shading, traffic and water cycles for each competition entry, and present the results prior to the jury meeting. These analyses - provided in the common format of single-domain expertise, yet unconventionally early in regards to the overall project timeline supplied deep empirical knowledge for the judgement process.

The application of the CityScope solution for the Grasbrook tender had to comply with the organisational and legal constraints. In addition to the issues described above, the secure storage and usage of the competitors' project data emerged as a key issue. Equally offered to all contestants as a support for their design and decision-making, the simultaneous access to the online tool as well as the data management on the platform's back-end system needed to comply with highest security and confidentiality standards. In view of legal controversies that frequently emerge in the aftermath of prestigious design competitions, the consortium treated data security and safety aspects with utmost rigor and reliability. To that end, secure user authentications, as well as individual usernames and passwords for each participant were implemented, while access to other participant's profiles or information was prevented.

Due to the scientific character of the cooperation project - which from the outset was scoped by all partners as an explorative endeavour - it was necessary to clearly distinguish the features and outputs of the CityScope solution from established expert tools commonly used e.g. for the simulation of traffic noise. When the CityScope was introduced to the competition teams, the aim and character of this parallel-running scientific experiment were directly communicated, and it was maintained that the solution would not deliver legally binding output or assessments.

\section{Theoretical Framework}

The CityScope solution presented here, and its application for the Grasbrook design competition, builds upon long-term research and cooperation between the scientific partners at MIT Media Lab and HafenCity University (HCU). As a shared focus of research in both institutions, the field of Digital City Science takes the digital transformation of urban life and space as a point of departure and explores new approaches for exploiting the growing amount of data and information for urban design and development. Within this framework, interactive tools for urban analysis and synthesis, such as CityScope, provide a key to the immense wealth of city data. Successful applications of such tools, for example in mass transportation planning or refugee accommodation (Noyman et al., 2017), have indicated their high practical potential in the urban context (Figure 2). The theoretical basis for these instruments, however, derives from two specific discourses on the digital city.

The first approach considers cities as complex systems with a holistic nature, in which individual elements are linked to each other either in the form of a relational network (Castells, 2004) or a self-regulating system (Sánchez, 2001) both of which possess specific degrees of organization (Rueda, 1995). Complex systems-approaches explicitly acknowledge the multiple network relations between elements of the different levels. For example, the construction of a building will affect its surrounding space by casting shadows, blocking noise, or retaining water - specific consequences which subsequently would affect the energy efficiency of the building as well as the thermal and noise comfort of the surrounding area. This, again, will impact on the willingness of residents to actively use the building and its neighbourhood.

The second theoretical approach understands urban space as a set of overlapping layers of information which form additional mental spaces on top of the physical substratum of cities (Duarte, 2017). In this sense, urban space is understood beyond the mere presence of buildings and streets, but also their impact on the urban system at both tangible - e.g. shadow, noise or rainwater - and intangible - e.g. comfort, popularity, identity - levels (Rapoport, 1977). For example, the construction of a new building is an intervention on the physical tangible layers of reality, which may affect the 
Figure 2. Allocating refugee accommodations with an interactive planning table from the Project "Finding Places." Copyright 2016 by Walter Schießwohl. Used with permission.

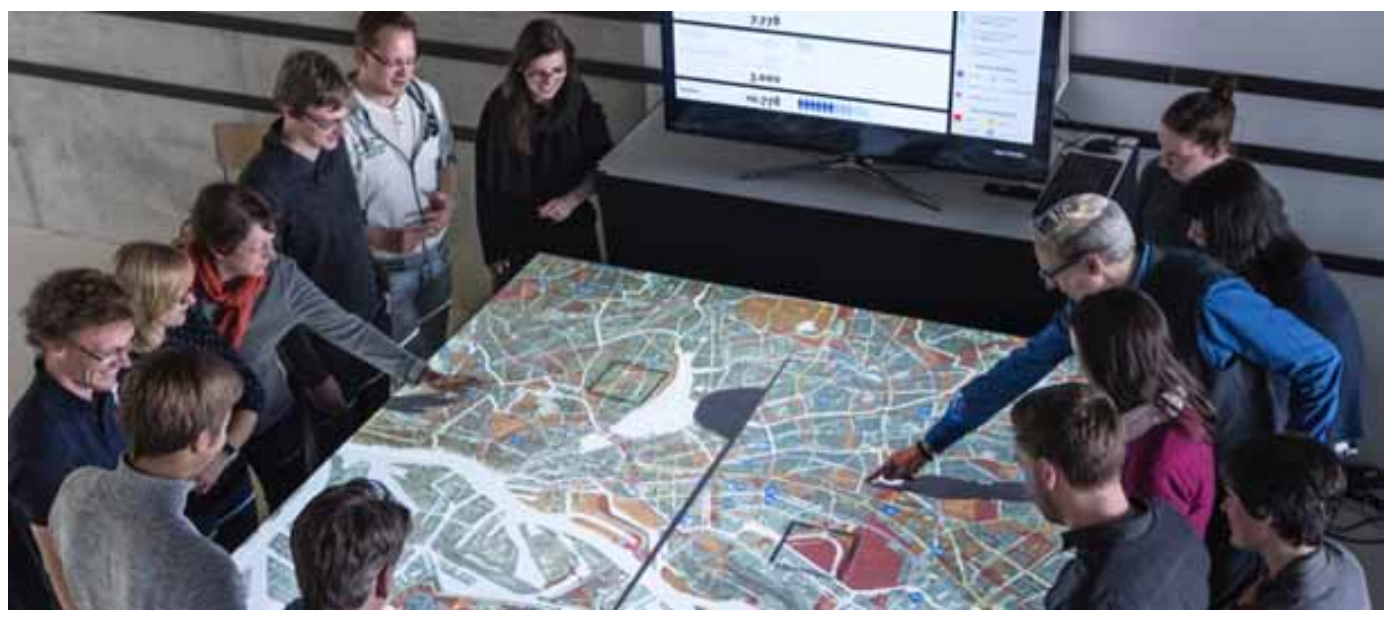

overall transport flow distribution at the urban scale, while also becoming a landmark that impacts on symbolic layers of the city by establishing itself as a new icon of identity.

Building on these frames of reference, the CityScope presents itself not only as a data-fed instrument that displays the network of urban processes and activities beyond the physical urban space but also as a platform for analytic tools whose interconnection enables an algorithmic analysis of complex cause-and-effect chains created by design interventions in urban fabrics. Conceived as a real-time interactive device, the CityScope aims to enhance early-stage design work with analytic intelligence that makes the progress towards optimal solutions more rapid and reliable.

\section{CITYSCOPE: PLATFORM FOR URBAN DESIGN ANALYSIS \& DECISION SUPPORT}

\section{Technical Description}

Conceived as an online platform for the visualization and analysis of urban complexity, the overall architecture of the CityScope solution consists of a front-end user interface plus a set of various backend tools or "Modules" (Doorley et al., 2019), all of which are connected via a data hub ("cityIO") (Noyman et al., 2019). This system architecture provides not only for standardized information exchange but also for a common programming interface which enables the modularized development of additional analytical modules, as well as the creation of project-specific frontend solutions. With this overall structure, different software applications for the analysis of specific urban qualities (e.g. noise distribution, stormwater runoff, pedestrian accessibility) or target indicators (e.g. Gross Floor Area, GFA) can be easily plugged-in yet independently developed. In order to allow maximum flexibility in choice of programming language, while ensuring compatibility modules are commonly conceived as dockerized applications that use simple http requests to get input from and post results to "cityIO". Figure 3 shows the general system architecture and data flow between the different components.

To improve the user accessibility and ease of use, the CityScope represents the information of an urban setting in the form of a grid. This abstraction enables faster calculations as well as real-time user interaction while maintaining the spatial logic of the urban setting. This transformation is performed by taking the morphology of the area and transferring the main volumes into a $2 \mathrm{D}$ raster of $16 \times 16$ meters and discretizing the height in steps of the projected story height (in the Grasbrook case: four meters for ground level, three meters on upper levels). Each grid cell thus contains information about 
Figure 3. Grasbrook CityScope System Architecture


the nature of space it represents (built, unbuilt) along with its main functions (residential, commercial, educational, promenade, street, park, etc.) as well as some other basic characteristics. In the context of the Grasbrook competition, the matrix of 16x16x[4/3] was determined as a feasible compromise between level-of-detail and technical considerations, informed by planning regulations, building code, and common architectural design patterns. It reflects (1) a standard measure for minimum street width according to heat flow and pollutant dispersion metrics (Yang \& Clements-Croome, 2017), (2) a building depth allowing natural cross-ventilation and daylight penetration (Merah \& Noureddine, 2019), (3) a suitable level of detail in the visualization of results with a feasible number of grid cells to allow for intuitive and time-efficient user input as well as real-time feedback for smooth user interaction, and (4) a documented metric for other similar cases of computational urban simulations (Sánchez et al., 2016).

\section{Analytic Modules}

For the long term, the CityScope is designed to become a holistic platform comprising a broad range of modules for the analysis and simulation of urban key parameters as well as for the complex interactions of physical and social environments. In close communication with the application partner HafenCity Hamburg $\mathrm{GmbH}$, however, four initial analytic modules were identified that were prioritized for the Grasbrook competition, targeting the analysis of noise propagation, stormwater runoff, walkability, and gross floor area (Figure 4). The selection was based on the assumption that these parameters would be key decision-making criteria for the Grasbrook competition, but also remain applicable to other urban planning ventures in the future. While these four modules were already implemented in the Grasbrook competition case (see the following paragraphs), additional modules are already being conceived and under development, for example for the analysis of local microclimate, social interaction, and human dynamics.

\section{Noise Module}

The distribution of noise emissions is a central concern in urban design and spatial composition. As the Grasbrook neighbours highly frequented city highways, train lines, as well as an industrial port area, the appropriate estimation of acoustic impact becomes a crucial issue (HafenCity Hamburg $\mathrm{GmbH}, 2019$, p. 89). In order to develop effective countermeasures - especially by way of designing appropriate spatial layouts - an easy assessment of early-stage urban design proposals is important. In conventional planning procedures without CityScope, first feedback on the noise performance of the design proposals is possible only by way of expert evaluation once the competition phase has been concluded.

The noise module developed for the Grasbrook CityScope, in contrast, is able to model noise propagation throughout the design area in near real-time. It considers noise emitters like large streets 


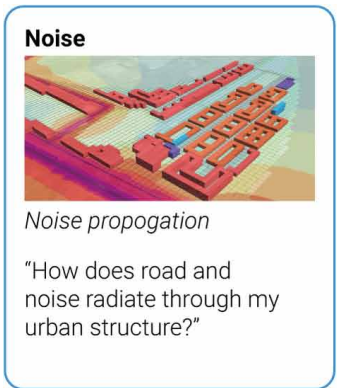



Annual runoff volumes

"How much stormwater runoff can I expect annually off of different surface types?"



and adjacent railway lines on the basis of expected local traffic loads. Traffic inside the area can be also added in accordance with individual design specifics.

The module uses software developed by the French Institute of Science and Technology for Transport, Development and Networks (Bocher et al., 2019), which is based on a simplified implementation of the French standard for urban noise propagation, NMPB-08 (Dutilleux et al., 2010; Association Française de Normalisation, 2011).

From the propositions entered by the designers via the online user interface, the noise simulation tool extracts building footprints and calculates a 2D noise distribution map. To do so, the noise emitted by simulated traffic on streets and railways is propagated through the design area, taking into account the diffractions and reflections caused by the buildings.

\section{Stormwater Module}

As the site of the Grasbrook district - and the city of Hamburg, more generally - is vulnerable to flooding caused by heavy rainfall events, the HafenCity Hamburg $\mathrm{GmbH}$ requested a stormwater module to be developed for the Grasbrook CityScope. The reason for considering stormwater during the early design phases is to prepare strategically for synergies between green stormwater infrastructure and achieving comfortable microclimatic conditions while meeting the functional requirements for the landscape design. This module calculates the surface runoff from each cell of the grid, aggregating the data to obtain an annual stormwater runoff volume associated with the design being analysed. To do so, each cell of the grid contains data about the surface type depending on the nature of space that it represents - e.g. building/street/open space - and each surface type is assigned a runoff coefficient. The runoff coefficients were adapted from Table 9 of DIN 1986-100:2016-12 (Deutsches Institut für Normierung e.V., 2016). The area of each cell $\left(\mathrm{m}^{2}\right)$ is multiplied by the runoff coefficient and by the annual rainfall $\left(\mathrm{m}^{3} / \mathrm{m}^{2} \cdot \mathrm{a}\right)$.

\section{Walkability Module}

Human-centred urban design strives for neighbourhoods that function effectively without broad usage of private vehicles. Thus walkability becomes a key parameter in the design of urban districts and neighbourhoods. In order to prevent unnecessary traffic and subsequent negative environmental impacts, basic amenities and socio-spatial infrastructure need to be accessible to all local residents within a short walking distance. In order to identify intelligent schemes for the placements and distribution of services and amenities already in the early phase of the urban design process, an analytic module was devised for the Grasbrook CityScope that calculates the 5-minute walkshed of special amenities such as educational facilities (local school), cultural destinations (museum) or daily suppliance (grocery store). The tool implements a standardized isochrone calculation using the walkable street network, a common method utilized in walkability and accessibility research (Dovey \& Pafka, 2020; Dovey, Woodcock \& Pike, 2017). 


\section{GFA Module}

A key indicator for the economic and spatial feasibility of urban design is the Gross Floor Area (GFA) generated by the respective proposal (Fan et al., 2018). Balancing the concerns of economic profitability (production of marketable real estate) versus spatial quality (openness, view, visibility), the iterative adjustment and optimization of the density of urban compounds is a key operation in urban design processes. The definition of GFA not only affects physical parameters e.g. distribution of light and shadow but local logistics and supply as well as the provision of social infrastructure, e.g. day-care or medical facilities. The CityScope's GFA module calculates the GFA dedicated to each use, or function, as defined in the competition design brief. On this basis, the module calculates the aggregated GFA in square meters in respect to the classification of building uses (residential, commercial, special other uses).

\section{Accuracy of Analyses}

With the implementation for the urban design tender of the Grasbrook district in Hamburg, the above-mentioned CityScope modules saw their first practical application in the context of highlevel international competition. This implied demands for the tool's quality and reliability, not only because the participating planning offices were officially requested to evolve their projects with the CityScope tools, but also because the competition jury expected reliable analytic assessment from the platform. The indication of result accuracy and reliability thus emerged as a core issue during the development and testing process. It was explained to all stakeholders early-on that the ambition was not to excel over expert tools (for nearly all target parameters more elaborate instruments are available). As the goal was to provide real-time analysis and instant decision support with satisfying accuracy in the early phase of urban design proposals, a feasible trade-off between usability, speed of interaction, and quality of assessment was needed. Throughout the development process of the tool, it was thus maintained that highest accuracy and reliability could only come from the expert reports of experienced consultants which, however, would take substantially longer time for producing and delivering reports to designers and jury.

The level of accuracy depends mostly on the process of how the concrete planning area is abstracted into the raster matrix of the CityScope, i.e. the relatively coarse 2D input raster of $16 \mathrm{~m}$ by $16 \mathrm{~m}$. Streets and buildings which do not fit these modular sizes or have curvy shapes and smaller volumes, need to be simplified into a lower resolution, thus losing design details. With this in mind, the definition of the accuracy of calculations becomes a necessary reference point for the reliable assessment of design scenarios. To clarify this issue, calculations performed with the CityScope were compared to the results of external reports prepared by a committee of experts. While the latter evaluated the performance of the design submissions in their original submission format, the input of proposals into the CityScope platform necessitated a simplification of design schemes due to basic grid structure, as mentioned above. The comparison - henceforth referred to as "Accuracy" - is evaluated for each module differently depending on the available data format from the expert evaluation.

\section{Noise Module Accuracy}

In the case of the Grasbrook competition, it was possible to directly compare the results of the CityScope noise module with the results delivered by an established consultancy with long experience in noise modelling. Figure 5 presents the results of the analysis of the winning competition entry performed with the CityScope tool compared to the results delivered by the external consultancy.

The visual comparison of both noise maps shows similar dispersal patterns. By rasterizing both result sets, a differential map is computed to locate and visualize the differences in estimated noise levels. The comparison of the results is performed under the consideration of all methods outputting results in the same measurement units. This differential map indicates that the total area of noise level differences greater than $10 \mathrm{~dB}$ are below $7.5 \%$ of the design area, whereas $53 \%$ of the design area 


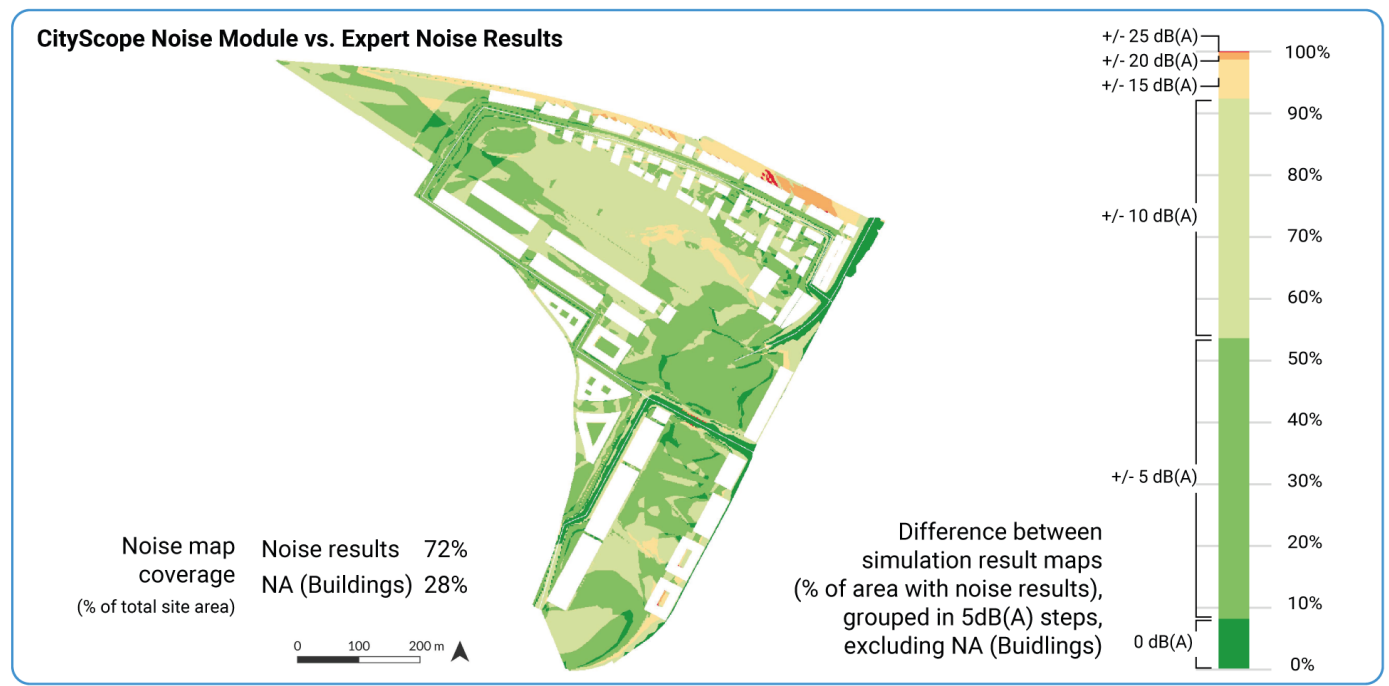

show deviations of max $5 \mathrm{db}$. The remaining $39.5 \%$ of the design area shows deviations between 5 and $10 \mathrm{~dB}$. As a general trend, the results delivered by the CityScope generally show lower noise levels than the ones delivered by the external consultancy. Still, a proportional behaviour and distribution of the noise levels underline the applicability of the tool under certain conditions.

Studies have shown that different experts evaluating the same situation with different national methods create results which deviate by $10-15 \mathrm{~dB}$ (Nijland \& Van Wee, 2005). In our case, a main cause for the deviation results is the different calculation methods used by the CityScope and the external consultancy, which differ, among other features, in the standard metrics utilized (Simplified implementation of the French NMPB-08 standard [CityScope] vs German RLS 90 standard for road noise sources and unspecified methods for propagation calculation [Consultancy]). Besides, various technical differences and input assumptions influence the definition of noise modelling accuracy, such as:

- Rasterized CityScope input format leads to simplifications of the design proposal from building footprints to a grid-based input.

- $\quad$ Expert's added higher noise levels to context-specific locations (e.g. Elbe bridges).

- French and German standards use different annotation scales for noise levels.

- CityScope delivers a composite day, evening and night index (LDEN) while the method deployed by the external consultancy indexes for daytime only.

\section{Stormwater Module Accuracy}

Currently, experts rely on schematic plans and excerpts of renderings to evaluate the stormwater management potential of submitted designs. These schematic plans, the minimum required submission according to the competitive dialogue brief (HafenCity Hamburg GmbH, 2020, p. 118), often lack the information necessary for experts to evaluate the submissions beyond a simple qualitative assessment. Going beyond such practices, the present CityScope module for the analysis of stormwater uses standardized measures of surface permeability and infiltration potential in order to estimate cumulative annual runoff volumes, results of which are visualized on a map and in a bar chart. While the expert analysis for water-cycles involves the qualitative assessment of schematic plans using a traffic light 
rating system, the CityScope enables a quantitative comparison of the design submissions in their entirety, while still supporting qualitative assessments (Figure 6).

Figure 6. CityScope map results map of runoff coefficients; estimated annual runoff volumes $\left[\mathrm{m}^{3}\right.$ ] by surface type. Upper Right: Qualitative evaluation method used to assess schematic map submissions; Adapted from HafenCity Hamburg GmbH (2019, p. 85)

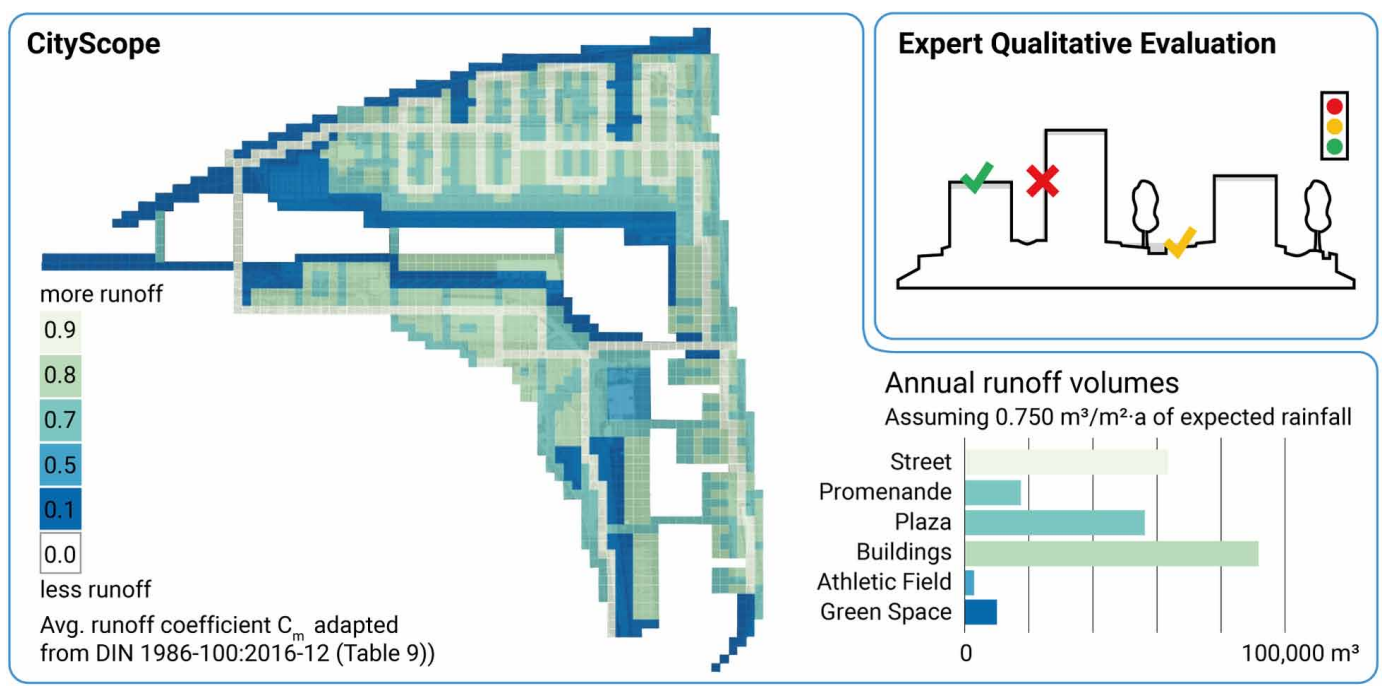

The aspects which the expert analysis regarded, however, were not consistently present in all design submissions, for example: (1) topography within the area; (2) directional flows within the stormwater network; (3) location and size of infrastructure like infiltration, retention, water treatment facilities, neighbourhood cistern. The present version of the stormwater module did not include these aspects, either. In future, the CityScope stormwater module should be expanded to include them in order to better support the qualitative and quantitative comparison of design submissions. Already in its current form, the stormwater module can deliver a valuable quantitative comparison of the designs in regards to the ratio of green and open space as well as annual runoff projections from differentiated surface types.

\section{Walkability Module Accuracy}

While the expert analysis was based on a qualitative evaluation of the pedestrian network, the CityScope numerically calculated the accessibility based on the morphology of the street network. Specifically, the module calculated accessibility from/to different amenity types (defined as buildings uses or functions) as the five-minute walking distance following the network of streets and open spaces. In the development of this module, three main walking profiles were defined: adult, child, and wheelchair user. Each of the walking profiles includes an average speed and a list of surfaces across which they are able to walk comfortably e.g. wheelchair users are not able to pass through cells with stairs. The calculation of walkability for each amenity type, and each walking profile, is performed using a flood fill calculation using Dijkstra's algorithm applied to grids (Eraghi et al. 2014) for finding the shortest path between nodes in a network, computing the distance from each amenity to all the other cells in the model. The CityScope walkability module enables quantitative analysis of accessibility (Figure 7), complementing the mostly qualitative interpretation provided by the mobility and transportation experts. 
Figure 7. CityScope map results for the walkability calculation using example user type adult and cultural institutions. Areas in green show the travel distance below the threshold of a five-minute walk. Upper Right: Qualitative evaluation method used to assess submission materials, including schematic maps, explanatory sketches, and pictograms (HafenCity Hamburg GmbH. 2019, pp. 78-81, 116)



\section{GFA Module Accuracy}

Due to the shape simplification imposed by the basic input grid of the CityScope, the accuracy of this module depends on the closeness of the design submission to modular sizes of 16 meters, straight lines, and right angles. The translation of design submissions into the CityScope grid had to acknowledge this condition which strongly determines the accuracy of the GFA analysis module (Figure 8).

Freeform-designs with variable building depths or street canyon widths achieve lower accuracy in the GFA analysis than designs based on rectangular blocks, due to deviations of the calculated floor area. In order to determine the accuracy of the model, calculations by the CityScope were compared with expert evaluation reports which include a cross-check of designed volumes against the definitions made by the competition brief (HafenCity Hamburg GmbH, 2019, pp. 50-53). The main use categories, "Commercial" and "Residential," correspond closely with the same use types in the competition brief, whereas the CityScope category "Other" roughly translates to "Special use," which includes cultural, educational, and sports use.

Differences in use type classifications between the CityScope and the competition brief, the transformation of the designs to the CityScope grid, and subjective data entry by users contributed to differences in GFA totals compared to the expert evaluation. In 7 of 8 instances, the absolute difference ranged from $1 \%$ to $27 \%$, with an average of absolute difference of $14 \%$. For one competition entry, the absolute difference was $170 \%$ for "Other" due to the user's interpretation of non-standard mixed use types as "Other" rather than primarily "Residential" or "Commercial." In future competitions, the GFA module should be more closely linked to the exact GFA requirements of the competition brief. That way, the module can provide a helpful signal to designer competitors to include all required uses while enabling the jury to rapidly and reliably evaluate submissions.

\section{DISCUSSION}

As described above, the CityScope tool Is implemented in two different use cases, namely (UC1) designers and planners developing urban proposals, and (UC2) competition juries evaluating the 
design of those proposals. The following section accounts for some general considerations, as well as specific assessment for each of the two use cases.

Figure 8. Translation of design submissions into CityScope grid



Translation of design submissions into CityScope

\section{Strengths}

The delay of expert analysis for key performance indicators is a major obstacle in the creation of feasible, sustainable and well-balanced proposals in the early stages of urban design work (UC1). The CityScope compensates this deficit by delivering analytic results to designers "on the fly" i.e. already during the design process. Providing real-time feedback about the performance of any presented proposal on a quality level sufficient for conceptual design phases, it allows quick testing, iterating and optimizing of design ideas while they are being produced. As CityScope works with one single data input which is shared across the different analytic modules, substantial time is saved on the side of designers as they do not need to input their design schemes several times into separate software applications, or carry out time-consuming data transfer and reformatting.

Providing a unified way for the ingestion of individual design proposals and for the subsequent quantitative analyses, the CityScope platform provides a standardized assessment of the complex environmental and social qualities of urban design proposals. Avoiding "apples to pears" comparison, it enables an objective assessment of naturally highly different proposals, which is particularly useful when there is need to evaluate several proposals under the same transparent criteria (UC2). The easy interaction and standard visualization make the analysis and comparison of proposals substantially more easy — not only for design juries and assessors but also for designers themselves. Without much effort, they can investigate the performance of individual proposals in regards to selected target indicators.

The standardized input and interaction formats as well as the explicit user guidance, plus the scientific models and algorithms at its basis, allow high transparency about the process of analysis and assessment in the CityScope. As a digital, data-based solution it creates high accountability in the context of design production and evaluation where the rationale of decision-making has often been unclear and opaque.

\section{Weaknesses}

The definition of the accuracy of the analytic modules remains a scientific and methodological challenge. End-users of the system like designers (UC1), juries (UC2), as well as developers, or investors depend on clear indications about the general reliability of the results, as well as of the relative 
reliability compared to the established means and methods for evaluation (as provided by professional software solutions or expert consultancies). While for the present CityScope solution sufficient validation could be delivered for the noise and rainwater modules, the discrepancy of scientific models, methodology, and data schemes, as well as a lack of information about basic assumptions, hamper their in-depth validation as well as the development and refinement of the other modules.

Even though one single data input into the CS system saves time compared to several data inputs in separate applications, the first version of the tool requires that the designs be manually into the CS tool (UC1 and UC2). This was accomplished by importing multiple layers of geospatial information (e.g. existing buildings, site restrictions), as well as the projected raster images of the first round designs, were included in the tool for users to "draw" on top of. It turned out to be a difficulty that the raster could not be rotated. This issue was solved in further editions of the tool. To make the input and translation process easier, Users expressed interest in being able to import data formats common for their preferred design software or the file formats required for the competition submission (DWG, RVT, IFC). In the near future, with careful planning and clean data, such a data conversion pipeline could be established for BIM file formats - considering the need to bridge its current limitations such as data semantics, or incompatible geometric notation.

\section{Opportunities}

A key benefit of the CityScope is its capacity to run comparisons and performance analysis across different layers of analysis at the same time. In this respect, the CityScope has substantially more analytic power than expert evaluations which usually consider only one dimension. Instead of evaluating a design proposal only by analyses of noise or GFA e.g. the platform allows complex combinations of target indicators (UC2). By changing the qualities of a plot or a building in one specific setting, impacts on many different other levels can be observed. By cross-connecting the various analytic modules, any new socio-spatial input will simultaneously change and update other layers of performance. By acknowledging and analysing these systemic interactions within the urban fabric, the CityScope provides a powerful tool for urban designers who need to shape and control this multiplicity (UC1). By adding extra layers of information as well as new analytic tools, the complexity of urban space can be far better addressed in future design work.

The validated scientific models and open-source software of the CityScope modules ensure that the evaluation of design proposals will not be delivered as a black-box mechanism. Instead, they give an explicit and rational basis for the results presented. In addition, their open-source character makes the modules easily adaptable to other future application scenarios. Apart from securing the transparency of the tool and process, the open-source concept also allows scientific and technical validation and constant improvement by the scientific community.

The interactive and iterative nature of the CityScope and its application makes it an appropriate instrument for multi-stakeholder engagement that may go beyond the hitherto involved set of actors, i.e. urban designers and developers, competition juries, and academic researchers (UC1). As a digital online tool, it has large potential to facilitate communication and dialogue also with larger stakeholders groups, for example, neighbourhood communities, local initiatives, or student circles. The facilitation of public engagement in urban planning is a central issue of Digital City Science. To this end, a CityScope with easy-to-use user interfaces and functionalities may become a key instrument.

\section{Threats}

The introduction of new work processes or technologies is commonly accompanied by scepticism, if not rejection, on the side of the target audiences. Design offices e.g. have their established approaches workflows; especially in the context of competition projects, they rely on conceptual and technical habits (UC1). Because the creation of competition entries usually happens under high time and work pressure, easy adoption of the new iterative, science- and data-based design procedure as proposed with the CityScope is not likely. Similarly, jurors and assessors will not necessarily welcome the 
appearance of new data-generated evidence about design proposals; discrepancies and conflicts between expert judgements and algorithmic analysis may occur. What is more, the replacement of expert judgements with informed expert interaction appears to be a thorough disruption of established market and power structures (UC2).

Market homogenization among the providers of architecture, design and engineering software may lead to an obsolescence of the presented tool and methodology. Although the potential integration of CAD, BIM and GIS systems may be highly desirable in terms of technological and methodological standardization and interoperability, and open up a wide arrange of new opportunities ranging from urban studies to city management and urban design, such convergence happening under the roof of some powerful software house may, however, lead to undue monopolization. Such exclusive market dominance may not only negate business competition but also the technological advancement by a larger research and development community. Examples of non-proprietary, open source solutions created in the past years (e.g. Open Street Map) have shown the massive impact that such applications can have. Science-driven endeavours like the one presented in this paper can contribute and support such developments with validated knowledge only if algorithms, data models and scientific assumptions are transparent and openly shared.

\section{CONCLUSION}

The CityScope is an ongoing attempt in "reinventing the competition" by way of an expandable digital solution for design analysis and assessment. With the case of Grasbrook tender in Hamburg, the project consortium has demonstrated its applicability in the framework of a high-level international urban design competition. Here, the new tool proved its capacity to effectively support the decision making of (1) designers and planners in the process of developing sustainable urban designs proposals, and (2) competition juries mandated for the evaluation of the same proposals. To both, the solution has supplied instant assessment and analytic evidence for four key criteria, and future effects resulting from design proposals could be estimated. The CityScope enabled fast iterations of design ideas and feasible trade-offs between target parameters. Thus, the solution has paved a way towards more holistic and interactive urban development processes, based on the fast prototyping of spatial and functional programs, as well as on their objective assessment.

Going beyond the conceptual phases of the Grasbrook urban design, as focussed-on in the first phases of the competition, a next-level application is envisioned for the subsequent functional planning phase. In this stage, instead of analysing schematic proposals, designs with higher complexity and level of detail will be treated, which in turn demand for yet higher accuracy on the side of the tool and method. In the functional planning of the district Grasbrook, the consortium will work hand in hand with the winning team of the design competition. Here, a key issue will be the transgression from the real-time analysis via the online platform to live interaction in (virtual) workshop settings with planners and developers. For this purpose, a third user interface and respective analytics need to be developed that can address the specific planning and communication demands of this planning phase. In the medium term, the CityScope solution will be applied to three different use cases: competition design, design jury and functional planning.

Apart from further application cases in the context of the Grasbrook urban development, next level scientific and technological goals have been outlined already. Reaching beyond performance assessments of physical and spatial-morphological properties, future editions of the CityScope shall also provide modules for the analysis of human interaction and social dynamics in urban environments. Current developments in social dynamic engines and agent-based simulations provide promising starting points for a novel level of performance analysis of urban designs. More than other solutions, the CityScope approach has the potential to deliver to planners and developers novel insights that emerge from the convergence of social sciences and urban design. 


\section{REFERENCES}

Alaily-Mattar, N., \& Thierstein, A. (2018). Urban transformations through exceptional architecture: Introduction to the special issue. Journal of Urban Design, 23(2), 165-168. doi:10.1080/13574809.2018.1429903

Alexander, E., \& Witzling, L. (1990). Planning and Urban Design Competitions: Introduction and Overview. Journal of Architectural and Planning Research, 7(2), 91-104. Retrieved September 5, 2020, from http://www. jstor.org/stable/43028959

Alrashed, T., Almalki, A., Aldawood, S., Alhindi, T., Winder, I., Noyman, A., Alfaris, A., \& Alwabil, A. (2015). An Observational Study of Usability in Collaborative Tangible Interfaces for Complex Planning Systems. Procedia Manufacturing, 3, 1974-1980. doi:10.1016/j.promfg.2015.07.243

Association Française de Normalisation. (2011). Acoustique-Bruit dans l'environnement-Calcul de Niveaux Sonores. AFNOR Standard No. NF S31-133.

Bocher, E., Guillaume, G., Picaut, J., Petit, G., \& Fortin, N. (2019). NoiseModelling: An Open Source GIS Based Tool to Produce Environmental Noise Maps. ISPRS International Journal of Geo-Information, 8(3), 130. doi:10.3390/ijgi8030130

Burdett, R., \& Rode, P. (Eds.). (2018). Shaping cities in an urban age. Phaidon Press Inc.

Burian, J., Stastny, S., Brus, J., Pechanec, V., \& Vozenilek, V. (2015). Urban planner: Model for optimal land use scenario modelling. Geografie (Utrecht), 120(3), 330-353. doi:10.37040/geografie2015120030330

Castells, M. (Ed.). (2004). The Network Society: A Cross-cultural Perspective. Edward Elgar Publishing. doi: $10.4337 / 9781845421663$

Christiaanse, K., Gasco, A., Hanakata, N. C., \& Acebillo, P. (2019). The grand projet: Understanding the making and impact of urban megaprojects. nai010 publishers.

Deutsches Institut für Normierung e. V. (2016). Drainage systems on private ground-Part 100: Specifications in relation to DIN EN 752 and DIN EN 12056. DIN 1986-100:2016-12. Retrieved from https://www.beuth.de/ en/standard/din-1986-100/264064948

Doorley, R., Noyman, A., Sakai, Y., \& Larson, K. (2019). What's your MoCho? Real-time Mode Choice Prediction Using Discrete Choice Models and a HCI Platform. UrbComp2019 - The 8th SIGKDD International Workshop on Urban Computing. Retrieved from: http://urban.cs.wpi.edu/urbcomp2019/accept.html

Dovey, K., \& Pafka, E. (2020). What is walkability? The urban DMA. Urban Studies (Edinburgh, Scotland), 57(1), 93-108. doi:10.1177/0042098018819727

Dovey, K., Woodcock, I., \& Pike, L. (2017). Isochrone Mapping of Urban Transport: Car-dependency, Modechoice and Design Research. Planning Practice and Research, 32(4), 402-416. doi:10.1080/02697459.2017. 1329487

Duarte, F. (2017). Space, Place and Territory: A Critical Review on Spatialities (1st ed.). Routledge. doi: $10.4324 / 9781315598888$

Dutilleux, G., Defrance, J., Ecotière, D., Gauvreau, B., Bérengier, M., Besnard, F., \& Duc, E. L. (2010). NMPBRoutes-2008: The Revision of the French Method for Road Traffic Noise Prediction. Acta Acustica united with Acustica, 96(3), 452-462. doi:10.3813/AAA.918298

Eraghi, N. O., López-Colino, F., de Castro, A., \& Garrido, J. (2014). Path length comparison in grid maps of planning algorithms: HCTNav, A* and Dijkstra. Design of Circuits and Integrated Systems, 1-6. .10.1109/ DCIS.2014.7035557

Fan, K., Chan, E. H., \& Chau, C. K. (2018). Costs and benefits of implementing green building economic incentives: Case study of a gross floor area concession scheme in Hong Kong. Sustainability, 10(8), 2814. doi:10.3390/su10082814

Hadhrawi, M., \& Larson, K. (2016). Illuminating LEGOs with Digital Information to Create Urban Data Observatory and Intervention Simulator. Proceedings of the 2016 ACM Conference Companion Publication on Designing Interactive Systems, 105-108. doi:10.1145/2908805.2909400 
HafenCity Hamburg GmbH (Ed.). (2019). Brieffor a Competitive Dialogue compliant to Article 18 VgV for an urban design parameter plan "Funktionsplan" and a landscape design scheme "Freiraumplanung” Grasbrook District in Hamburg (C. Ahrens, Trans.). Reproplan Hamburg GmbH. Retrieved from: https://www.grasbrook. de/wp-content/uploads/2020/08/Englisch_Auslobung_Grasbrook_Version_Digital-1.pdf

Haugbølle, K., Pihl, D., \& Gottlieb, S. C. (2015). Competitive Dialogue: Driving Innovation Through Procurement? Procedia Economics and Finance, 21, 555-562. doi:10.1016/S2212-5671(15)00212-9

Lehmann, S. (2019). Urban Regeneration: A Manifesto for transforming UK Cities in the Age of Climate Change. Palgrave Macmillan., doi:10.1007/978-3-030-04711-5

Merah, A., \& Noureddine, A. (2019). Reactive pollutants dispersion modeling in a street Canyon. International Journal of Applied Mechanics and Engineering, 24(1), 91-103. doi:10.2478/ijame-2019-0006

Nijland, H. A., \& Wee, G. P. V. (2005). Traffic Noise in Europe: A Comparison of Calculation Methods, Noise Indices and Noise Standards for Road and Railroad Traffic in Europe. Transport Reviews, 25(5), 591-612. doi:10.1080/01441640500115850

Noyman, A. (2015). Powerstructures: The Urban Form of Regulation [Master's dissertation]. Massachusetts Institute of Technology. https://dspace.mit.edu/handle/1721.1/99301

Noyman, A., Holtz, T., Kröger, J., Noennig, J. R., \& Larson, K. (2017). Finding Places: HCI Platform for Public Participation in Refugees' Accommodation Process. Procedia Computer Science, 112, 2463-2472. doi:10.1016/j. procs.2017.08.180

Noyman, A., Sakai, Y., \& Larson, K. (2019) CityScopeAR: Urban Design and Crowdsourced Engagement Platform. Cornell University: Retrieved from: https://arxiv.org/abs/1907.08586

Pánek, J., Pászto, V., \& Marek, L. (2017). Mapping emotions: spatial distribution of safety perception in the city of Olomouc. In The rise of big spatial data (pp. 211-224). Springer. doi:10.1007/978-3-319-45123-7_16

Rapoport, A. (1977). Human aspects of urban form towards a man-environment approach to urban form and design (1st ed.). Pergamon Press.

Rueda, S. (1995). Ecología urbana: Barcelona i la seva regió metropolitana com a referents. BETA Bulletin of Experimental Treatments for AIDS.

Sanchez, B., Santiago, J. L., Martilli, A., Palacios, M., \& Kirchner, F. (2016). CFD modeling of reactive pollutant dispersion in simplified urban configurations with different chemical mechanisms. Atmospheric Chemistry and Physics, 16(18), 12143-12157. doi:10.5194/acp-16-12143-2016

Sánchez, J. R. (2001). Sistemas urbanos complejos. Acción y comunicación. Cuadernos de Investigación Urbanística, 32, 1-76.

Yang, T., \& Clements-Croome, D. J. (2018). Natural Ventilation in Built Environment. In R. Meyers (Ed.), Encyclopedia of Sustainability Science and Technology. Springer. doi:10.1007/978-1-4939-2493-6_488-3 
Jesús López Baeza holds a PhD in Architecture. He works as Science Lead at HafenCity Universität Hamburg, and Project Architect in SPIN Unit Lab Helsinki. He has led and participated in several national and international projects in Europe and Asia. Part of his work encompasses social cohesion, activities and livability of urban spaces, and citizen preferences in urban public spaces, urban identity production, spatial perception, agent-based modeling, among other dynamics in the field of advanced socio-spatial analysis.

Julia Sievert is a research associate at HafenCity University in Hamburg, Germany. She holds a B.A. in Environmental Studies from Knox College (Illinois) and an M.Sc. in Resource Efficiency in Architecture and Planning (REAP) from HafenCity University.

Andre Landwehr studied Sustainable Urban Management at Malmö University in Sweden, as well as industrial engineering at the University of Applied Sciences Emden / Leer/Oldenburg. After completing his studies, he worked for two urban innovation and participation projects at the environmental authority of the city of Malmö. Before studying and working in Sweden, as well as afterwards, he worked for a Hamburg company for the conception and development of online tools in the field of technical building equipment and energy efficiency.

Jonas Luft graduated in computer science from the Technical University of Berlin. He is a research associate at the CityScienceLab since November of 2018 and investigates computational approaches to societal challenges, specialising in geospatial analyses and computer vision.

Philipp Preuner works for HafenCity Hamburg $\mathrm{GmbH}$, a city-owned urban development corporation, where he focuses on urban sustainability and innovation issues on a district scale. He graduated from the MSc Resource Efficiency in Architecture and Planning at HCU Hamburg following a double undergraduate degree in Anthropology and Economics in Vienna and Hong Kong. Before joining HafenCity Hamburg GmbH, he worked for UN-Habitat and the International Institute of Applied Systems Analysis on integrative urban development issues.

Jürgen Bruns-Berentelg has been Chairman of the Executive Board of HafenCity Hamburg GmbH since 2003. HafenCity Hamburg is one of the most important international city and waterfront development projects. The aim is to create an outstanding, sustainable "New Downtown" in the tradition of European urbanism. As a mixed-use new district, HafenCity will extend Hamburg's city center by 40 percent, creating $10.5 \mathrm{~km}$ of new public promenades along the waterfront. Before joining HafenCity Hamburg $\mathrm{GmbH}$, Jürgen Bruns-Berentelg held management and board positions with British, American, and German real estate companies. He has also worked on major projects such as the new central station in Berlin and the Sony Center at Potsdamer Platz, also in Berlin. Jürgen BrunsBerentelg studied geography and biology; he is also a real estate economist. In 2014, he was appointed Professor of Integrated Urban Development at HafenCity University Hamburg.

Ariel Noyman is an Urban Scientist, working to fuse cities and technology. His research is on novel methods of urban modeling and simulation, future mobility, and decentralized decision-making. In recent years, Noyman has coordinated and deployed a worldwide network of City Science Living-Labs, in Hamburg, Shanghai, Andorra, Helsinki and Guadalajara to name a few, in an effort to confront his research with real-world challenges. Noyman's work received awards from the European Commission, the OECD, the Chinese and the Israeli Gov., was featured by The Guardian, 60 Minutes, The New York Times and was displayed in exhibitions, conferences and summits worldwide. He's currently completing his PhD at the MIT City Science Group, as well as lecturing at MIT, Northeastern University, and Bezalel Academy in Jerusalem. Noyman holds a Master of Science from MIT and a Bachelor in Architecture (cum Laude) from Bezalel Academy in Jerusalem.

Jörg Rainer Noennig is Professor of Digital City Science at Hafencity University Hamburg and Director of the Wissensarchitektur Laboratory of Knowledge Architecture at TU Dresden. Between 1998 and 2001 he practiced as an architect in Tokyo, among others at Ishiyama Experimental Underground Architecture Factory and Arata Isozaki \& Associates. From 2001, he was a research associate at TU Dresden, where he was appointed Junior Professor of Knowledge Architecture (2009-2015). Jörg Rainer Noennig has published several books and more than 100 academic papers and essays, won several prizes, scholarships, and awards, including the Grand Prix of the European Association for Architectural Education (EAAE). 